\title{
ABRAHAM FIRKOVITSH OCH HANS SAMLINGAR I ROSSIJSKAJA NACIONAL'NAJA BIBLIOTEKA I S:T PETERSBURG
}

\author{
Tapani Harviainen
}

Helsingfors

\begin{abstract}
Abraham ben Shemuel Firkovitsh (Reshef, 1787-1874) var en av de mest framgångsrika samlarna av manuskript och antikviteter som orientalistikens historia känner. Firkovitsh föddes i Lutsk i nordvästra hörnet av nuvarande Ukraina. Till religionen var han karait och hans modersmảl var karaimska som hör til de turkiska språken. ${ }^{1}$ Abraham Firkovitsh fick en traditionell utbildning som gav honom grundliga kunskaper $i$ hebreiska språket och litteraturen. $\dot{A}$ andra sidan studerade han aldrig vid en akademisk institution.

I början av 1800-talet strävade karaiterna i Ryssland efter att framhäva sina traditionella särdrag i motsats till de judiska massorna som efter Polens delningar hade blivit ryska undersåtar. Firkovitsch ville visa att karaiterna hade djupa rötter i Ryssland, att de inte var judar till sitt ursprung och att de sảledes inte borde hamna under samma restriktioner som gällde judarna $\mathrm{i}$ landet.

Firkovitsh' personarkiv ligger bland hans andra samlingar i Ryska nationalbiblioteket i S:t Petersburg (f d Saltykov-Shchedrins offentliga bibliotek - Publichnaja biblioteka im. Saltykova-Shchedrina i Leningrad).

I arkivet finns mer än tusen brev skrivna av eller till Abraham Firkovitsh; de flesta av dem behandlar hans resor och upptäckter. Ändå vet vi mycket litet om hur Firkovitsh gick tillväga fōr att övertyga ägarna av handskrifter, gravinskriptioner och andra antikviteter att ōverlāmna sina dyrbarheter just til honom på Krim, i Derbent, Aleppo, Jerusalem, Nablus, Cairo m.m. I detta henseende var han totalt unik. I jämförelse med andra samlare av judiska manuskript var Firkovitsh också tidigare ute och kunde därfōr i många fall skumma grädden av vad som fanns. ${ }^{2}$
\end{abstract}

Av den färks litteraturen om karaiterns, deras historia, religion, nationalitet, sprák osv, nämner jag här endast tvả óversikter: Simon Szyszman, Les Karaites d'Europe (Acta Universtatis Upsaliensis. Studia Multiethnica Upsaliensia 7. Uppsala 1989) och Nathan Schur, History of the Karaites (Beiträge zur Erforschung des Alten Testaments und des antiken Judentums, Band 29. Frankfurt am Main, Berlin, Bern, New York, Paris, Wien 1992).

Jacob Sappir shittadex Kairo-genizan 1864, fastān Abraham Firkovitsh besökte den redan samma àr (se foljande not) och Adler, Neubauer, Cowley och Schechter stömdex den först pá 1890-talet. Om Firkovitsh' resor och samlingsverksamhet kan läsas mera i V.V. Lebedevs artikel $>$ Novye dannye o sobiratel'skoj dejatel'nosti A. S. Firkovichak (Vostochnyj sbomik GPB, Vypusk 4, Leningrad 1990, p. 32-44) och specielt om hans forthllande til karaiteme i Hit och deras arkiv i $T$. Harviainens Abraham Firkovitsh, Karites in Hit, and the Provenance of Karaite Transcriptions of Biblical Hebrew Texts into Arabic Script, Folia Orientalia XXVIII, 1991, Studies in Memory of Andrzej Czapkiewicz 1, Wroclaw - Warszawa - Kraków 1992, p. 179-191.

V.L. Vikhnovich och V.V. Lebedev har skrivit en biografi Zhizn i stranstrija Aben Reshefa ['Livet och vandringarna av Aben Reshef (= A. Firkovitsh)'] som baserar sig pa Firkovitsh' personarkiv; p.g.a. bristande resurser har forlaget Nauka i Moskva tillsvidare inte utgivit boken. 
Firkovitsh hade rest och samlat böcker och handskrifter i Orienten i 35 år, när han 1862-63 sảlde sin Första samling till Kejserliga offentliga biblioteket (nuv. Ryska nationalbiblioteket) i S:t Petersburg.

1863 reste den 75-årige Firkovitsh igen till Syrien och Palestina, Aleppo, Jerusalem och Nablus och därefter till Kairo. Av hans brev att döma är det uppenbart att han under denna resa skaffade sig handskrifter hos den berömde Jemen-forskaren Jacob Sappir i Jerusalem, av karaiterna i Hit i Mesopotamien som hade kommit till Jerusalem samt hos samaritanerna i Nablus. Senare arbetade han i Egypten ảtminstone två månader i haggeniza i den karaitiska synagogan i Kairo och dārefter hoppades han kunna »utgräva* genizan (le-hosi' 'et hag-geniza mit-tahat ha-'afar) i Ben-Esra synagogan som sedermere blev bekant som the Cairo Genizah. ${ }^{3}$ I allmänhet har man antagit att majoriteten av Firkovitsh' samlingar härrör frăn Kairo-genizan, men denna uppfattning har nu visat sig vara ätminstone delvis felaktig. Däremot har det blivit uppenbart att genizan i Ben-Esra synagogan inte var så enastående som vi har tänkt oss hittills och att det fanns ett större antal förråd av dyrbara manuskript i Främre Orienten. I dag är bilden mycket mera mångfasetterad än för bara ett par år sedan.

Firkovitsh sålde sina samaritanska samlingar till Kejserliga offentliga biblioteket i S:t Petersburg ăr 1870. De införlivades som en självständig enhet i den Första Firkovitshsamlingen.

Abraham Firkovitsh dog i Chufut-Kale (Bahchisarai) på Krim år 1874. Efter hans dōd köptes hans Andra samling ännu samma år av Kejserliga offentliga biblioteket. Ett år senare uppstod den stora kontroversen om äktheten av Firkovitsh' fynd, vilket innebär att Firkovitsh själv aldrig hade tillfälle att fōrsvara sig mot de hätska anklagelser som speciellt $\mathrm{A}$. Harkavy, bibliotekarien som var ansvarig för Firkovitsh-samlingarna, och Ephraim Deinard, Firkovitsh' f d hjälpreda och medarbetare, riktade mot honom. Fortfarande bär namnet Firkovitsh stämpeln av en mästarförfalskare. ${ }^{4}$

\section{Samlingarna}

Enligt den färskaste rapporten av Viktor Lebedev består Firkovitsh-samlingarna av 17.000 enskilda manuskript alltifrản stora kompletta handskrifter till små fragment av en sida. ${ }^{5}$

3. Först i Kairo studerade han (varje dag) arabiska som tedde sig för honom som ett oerhört vidstrāckt sprak, som spiramiden*; for arabiskans skull hade han inte tid att studera franska. Personarkiv (F. 946), nos. 605 och 610 .

- Ändł har man funnit mycket fă dokumenterade förfalskningar i hans samlingar. Det är sannolikt att Firicovitsh $i$ sin iver att finna urgamla texter blev atminstone lika ofta offer för orientaliska forfalskare som han själv försōkte göra nàgra fă kolofoner ett par hundra àr äldre. Däremot finns det inga bevis pa föralskade handskriftstexter. Da Firkovitsh saknade akademisk utbildning, skulle hans forfalskningar sannolikt ha avslöjats snabbt och utan svårigheter. Se Harviainen 1991/1992, p. 179 180 och n. $5-6$, p. 187.

5 Viktor Lebedev, sidishe ksavyaden in der leningrader efentlekher bibliotek* (Sovjetish hejmland. 11/1989, p. 154-158), p. 154-155. Tidigare har K.B. Starkova utgett en beskrivning av samlingarna: -Rukopisi kollekcij Firkovicha Gosudarstvennoj publichnoj biblioteki im. M.E.Saltykova-Shchedrinac (Pis'menuye pamjatniki vostoka, Istoriko-filologicheskie issledovanija, Ezhegodnik 1970, Moskva 1.974, p. 165-192) och > Les manuscripts de la Collection Firkovixa (Revue des Etudes Juives, 134, 1975, p. 101-117). 
Det finns ingen katalog som skulle täcka hela den digra samlingen; de viktigaste katalogerna förekommer i noterna till denna artikel. ${ }^{6}$ Utöver dem har biblioteket en rad maskineller handskrivna inventarielistor och kartotek vilka inte alltid är lätthanterliga eller fullt pålitliga. Det är fortfarande möjligt att göra intressanta upptäckter i Firkovitsh-samlingarna och detsamma gäller Ryska nationalbiblioteket i dess helhet. ${ }^{7}$

De manuskript jag har sett befinner sig i varierande tillstånd. En del av dem är fulla av maskhål, andra ār bara smutsiga och i behov av putsning och en del är väl konserverade. Så vitt jag ser, är samlingarna inte utsatta för fara att förstöras.

I samlingarna finns material på följande språk: hebreiska, arameiska, arabiska, persiska, jiddish, karaimiska och krimtshakiska (Krim-judarnas tatariska). Oberoende av språk (arabiska, karaimska osv.) har det stora flertalet av handskrifterna skrivits med hebreiska bokstäver. Det mest betydande undantaget är de samaritanska manuskripten i vilka man har använt det samaritanska alfabetet fōr både hebreiska, arameiska och arabiska. En del av de arabiska texterna har skrivits med arabisk skrift. ${ }^{8}$ Ett specialfall utgōr de karaitiska transkriptionerna av hebreiska texter som är skrivna med arabiska konsonanter och vokaliserade med hebreiska vokaltecken - sprảket är ändå hebreiska. ${ }^{9}$ Daterade manuskript täcker en period som sträcker sig från 900 -talet till 1800 -talet.

Den första Firkovitsh-samlingen innehåller en stor māngd väl bevarade omfattande manuskript av Bibeln och den centrala judiska och karaitiska litteraturen. Den berömda Codex Leningradensis som har utgivits i Biblia Hebraica Stuttgartensia (BHS), grundtexten till den hebreiska Bibeln, hōr till denna samling och är signum I Firk. B $19^{A} .^{10}$ Den samaritanska

6 A. Harkavy föberedde en katalog omfattande 4000 (eller 6000 ?) sidor över samlingama men hans verk blev inte publicerat och manuskriptet förvann pa 1930-talet; enligt V. Vikhnovich har katalogen hittats i den Ukrainska Vetenskapsakademins bibliotek i Kiev i ar, jmf V. Vikhnovich, >Vu gefint zikh Harkavis vikhtikste verk?^ (Sovjetish Hejmland, 3/1989, p. 132-134) och >Gde nahoditcja glavnyj trud Garkavic (Sovjetish Hejmland, 2/1991, p. 36-38) samt hans föredrag $>$ New Aspects on the Relationship between A. Firkovitsh, D. Khvolson and A.A. Harkavy i Eleventh World Congress of Jewish Studies i Jerusalem 28.6.1993 (utkommer i kongressens Proceedings nästa år), āven personligt meddelande i brev 26.4.1993.

7 Det är nyttigt att lägga märke till det faktum att Firkovitsh-samlingarna ändà utgör endast en liten del av manuskriptavdelningen i biblioteket och att manuskriptavdelningen med sin lilla läsesal är bara ett höm i den kolossala byggnaden vid Nevskij Prospekt. I biblioteket finns det ocksá judiskt handskriftsmaterial fràn von Tischendorfs (1858), Antonins (Andrei Kapustin, frín Kairo-genizan, 1899), Bahchisarais historiska arkitektumuseums (1976) och Jevsej Peisahs (krimtshakiska manuskript, 1984) samlingar.

3 Viktor Lebedev, Arabskie dokumenty IX-XX vv. Katalog (Ministeratvo bultury RSFSR. Goudardvennaja ordena trudovogo krasnogo znameni Publichnaja biblioteka im. M.E. SaltykovaShehedrina. Leningrad 1978).

9 Tapani Harviainen, Karaite arabic Transcriptions of Hebrew in the Saltykov-Shchedrin Public Library in St. Petersburg * [Estudios Masóreticos (X Congreso de la IOMS). En memoria de Harry M. Orlinsky. Editados por Emilia Fernández Tejero y Maria Teresia Ortega Monasterio. Textos y estudios Cardenal Cisnerosa de la Biblia Políglota Matritense (TECC) 55 . Instituto de Filología del CSIS, Madrid 1993, p. 63-72].

10 Om bibelhandskriftems se A. Harkavy und H.L. Strack, Catalog der hebräischen Bibelhandschriften der Kaiserlichen Öffentlichen Bibliothek in St. Petersburg. Erster und zweiter Theil (St. Petersburg Leipzig 1874). 
samlingen omfattar 1350 handskrifter (18.000 folier) vilka ār i många hänseenden enastående. ${ }^{11}$ Den stōrsta delen (över 7000 texter) av den Andra Firkovitsh-samlingen (nästan 14.000 texter) har skrivits på judisk arabiska, dvs pả arabiska men med hebreiska bokstäver; deras språk avslöjar ofta dialektala drag som genom sin avvikelse från den klassiska arabiskan gör dessa texter till en viktig källa även fōr spräkvetenskapen. ${ }^{12}$ Över 2000 bibelkodexar och andra bibliska texter ingår i den Andra samlingen; Lyons universitet $\mathrm{i}$ Frankrike har ett projekt för publiceringen av en fullständig katalog över dessa texter.

Teman som förekommer i Firkovitsh-samlingarna omfattar praktiskt taget alla kunskapsområden som fanns vid tiden för texternas uppkomst. Termer som bibelhandskrifter, biblisk exeges, Mishna, Talmud, midrash, halakha, bönböcker, ketubbot, historia, filosofi, teologi, religiös polemik, naturvetenskap, fysik, matematik, astronomi, astrologi, medicin, filologi, grammatik, ${ }^{13}$ skōnlitteratur, folklore och poesi markerar de viktigaste ämnesgrupperna. ${ }^{14}$

Även denna korta beskrivning torde visa att varje orientalist kan finna material från sina intresseområden i Firkovitsh-samlingarna. Ändå har endast några fả forskare frản Norden begagnat sig av denna geografiskt så närliggande möjlighet. Att arbeta i S:t Petersburg är inte oproblematiskt. Detta beror på praktiska omständigheter i staden samt möjligheten att fả tilstånd att använda material i manuskriptavdelningen i det Ryska nationalbiblioteket. Tillstånd förutsātter en inbjudan från biblioteket. I avdelningens läsesal finns det inte rum för mer än 40 personer. Kopieringsmöjligheterna är begränsade och tillgången till mikrofilmer är komplicerad. Fortfarande är blyertspennan ett effektivt hjälpmedel vid arbete i biblioteket.

The Hebrew University i Jerusalem har underhandlat om tillstånd att mikrofilma alla samlingarna och fotograferingen skulle bōrja på hōsten 1993. Ändå ger mikrofilmerna endast en del av sanningen och många projekt kan fullbordas endast med hjälp av själva manuskripten. Trots alla komplikationer som kan uppstå är arbetet med de ākta kāllorna, handskrifterna i S:t Petersurg en erfarenhet som vi för bara tio år sedan endast kunde drōmma om. Nordiska vetenskapssamfund skulle kunde bidra med att förmedla inbjudningar att forska vid Ryska nationalbiblioteket - adressen är: 18 Sadovaya, 191069 S:t Petersburg, Ryssland. Fastān det behövs tid och tảlamod till att fylla $i$ formulär för sådana

if Haseeb Shehadeh, Din we-hešbon rišoni 'al 'osef kitbe hay-yad haš-šomroniyyim be SantPetersburg«. Föredrag i Eleventh World Congress of Jewish Studies, Jerusalem 23.6.1993 (utkommer i kongressens Proceedings nästa år). Om tidigare kataloger m.m. se även Samaritjanskie dokymenty Gosudarstvenoj publichnoj biblioteki imeni M.E. Saltykova-Shchedrina - Katalog (av L.H. Vil'sker och V.V. Lebedev. Ministerstvo kultury RSFSR. Gosudarstvennaja ordena trudovogo krasnogo znameni Publichnaja biblioteka im. M.E. Saltykova-Shchedrina. Sankt-Petersburg 1992).

12 Det finns två publicerade inventarielistor över dessa handskrifter. Victor Lebedev, Arabakie sochinenija v evrejski grafike. Katalog rukopisej (Ministerstvo kultuty RSFSR. Gosudarstvennaja ordena trudovogo krasnogo znameni Publichnaja biblioteka im. M.E. Saltykova-Shchedrina. Leningrad 1987) och Y.Y. Yanons (P.B. Fenton) preliminära Rešimat kitbe-yad ba-'arabit-yehudit beLeningrad: rešims 'ara'it šel kitbe-yad ba-'arabit-yehudit be'ospe Firq̧obis (Makon Ben-Ṣebi, Jerusalem 1991).

13 M.N. Zislins publikation av den karaitiska grammatiken Me'or 'ajin (Pamjatniki pis'mennosti vostoka, XCVI, Moskva 1990) är ett fint exempel pa detta slags vetenskap. 
anhảllanden och förfrảgningar, är de potentiella resultaten sådana att det lönar sig att göra det āven flera gånger om. 